\title{
Readers of histone modifications
}

\author{
Miyong Yun ${ }^{1}$, Jun $\mathrm{Wu}^{1}$, Jerry L Workman ${ }^{2}$, Bing $\mathrm{Li}^{1}$ \\ ${ }^{I}$ Department of Molecular Biology, UT Southwestern Medical Center, Dallas, TX 75390-9148, USA; ${ }^{2}$ Stowers Medical Research \\ Institute, Kansas City, MO 64110, USA
}

Histone modifications not only play important roles in regulating chromatin structure and nuclear processes but also can be passed to daughter cells as epigenetic marks. Accumulating evidence suggests that the key function of histone modifications is to signal for recruitment or activity of downstream effectors. Here, we discuss the latest discovery of histone-modification readers and how the modification language is interpreted.

Keywords: histone modification; chromatin; epigenetics

Cell Research (2011) 21:564-578. doi:10.1038/cr.2011.42; published online 22 March 2011

\section{Introduction}

Most eukaryotic DNA is wrapped around histone proteins to form chromatin, a stable structure that limits DNA accessibility to its binding partners. Histones are subject to posttranslational modifications (PTMs), and these modifications are important parts of regulatory circuits that control chromatin dynamics and the activities taking place with the underlying DNA [1]. Histone modifications also function as epigenetic passengers that can be inherited by daughter cells to maintain lineagespecific transcription profiles [2]. Thus, understanding functions of histone modifications has become a central focus of the chromatin field [3].

Modifications on histones can directly influence chromatin structure. For instance, acetylation on lysine residues can reduce the positive charge of histones, thereby weakening their interaction with negatively charged DNA and increasing nucleosome fluidity [4]. Even acetylation on a single residue (H4K16) can alter the compaction level of a nucleosomal array [5]. Moreover, the diverse chemical moieties involved in histone PTM and modification sites have led to the proposal of the histone code hypothesis $[6,7]$. It postulates that PTMs function as a signal platform to recruit effector modules to local chromatin, and it is the effectors/readers that ultimately determine the functional outcome of certain PTMs.

Correspondence: Bing $\mathrm{Li}$

Tel: +1-214-648-1668; Fax: +1-214-648-1490

E-mail: Bing4.Li@utsouthwestern.edu
Over the past 10 years, the field has discovered multiple families of conserved domains that recognize modified histones. Biochemical and biophysical studies have revealed a wealth of details on how individual domains interact with modified histone peptides [8]. However, deciphering the language of histone PTM is much more than matching histone marks with their binding partners. The biological outcome of certain PTMs often heavily depends on the chromatin and cellular context of such modifications [9].

In this article, we will provide an overview of recent advances in reading histone modifications and highlight studies that influence the view of the field. We first review key experimental approaches that led to identification of PTM readers. Although a comprehensive list of PTM-recognition domains is provided, we will mainly focus on common themes of interactions and the importance of chromatin context. Next, we discuss how individual recognition modules are utilized by a functional complex to interpret PTM language and explain why multivalent recognition emerges as a prevalent mechanism. Finally, we summarize how to regulate PTM reading and functional outcomes of histone modifications.

\section{Looking for readers}

Bromo domains were initially found in nuclear histone acetyltransferases (HATs) but not in cytoplasmic HATs, which led to the speculation that bromo domains may recognize acetylated histones in chromatin. Dhalluin et al. went on to demonstrate for the first time that bromo domains preferentially interact with $\mathrm{H} 4 \mathrm{~K} 8$-acetylated 
histone peptides [10]. Since then, samplings between conserved domains in chromatin-related proteins and chemically modified histone peptides revealed several PTM readers, such as the double-bromo domain of TAF1 (which recognizes acetylated histones) [11] and the chromo domain of HP1 (recognizing H3K9me) [12]. This trend continued until a high-throughput candidatebased approach was developed. Protein microarrays that carry a large number of chromatin-related domains were produced to accelerate the reader-screening process. Using a series of fluorescence-labeled modified histone peptide probes, Tudor and MBT domains were identified as new classes of methyl-lysine (MeK) readers [13]. As a complementary method, peptide microarrays that contain modified and unmodified histone peptides were used to discover several new members of the Tudor domain family that can read MeK [14].

Despite robustness of the approach described above, unbiased screening methods are more desirable to discover unpredictable matches between PTMs and their readers. In one strategy, immobilized histone peptides were used as baits to retrieve their recognition proteins from nuclear extracts, and MDC1 was identified as a novel binder for phosphorylated $\mathrm{H} 2 \mathrm{AX}(\gamma \mathrm{H} 2 \mathrm{AX})$ peptides [15]. Conversely, a chromatin-associated protein, 53BP1, was used as a bait to look for specifically modified histones from purified native core histones [16]. The authors discovered that 53BP1 preferentially binds to H3K79me, based on mass-spectrometry analysis [16]. Recently, a quantitative proteomics method has been developed to improve unbiased PTM reader screens [17]. In this so-called SILAC ( Stable Isotope Labeling by

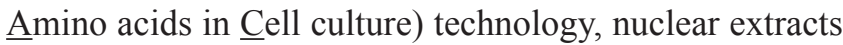
from "Heavy"-labeled cells are incubated with modified peptides, whereas "Light"-labeled extracts are incubated with unmodified peptides. Pull-down assays are performed separately. Enriched proteins are mixed before being analyzed by mass spectrometry, which allows a quantitative comparison between binders for unmodified histones and modification-specific binders [17]. Using this method, the authors provided a comprehensive list of readers for several transcription-related modifications such as active marks $\mathrm{H} 3 \mathrm{~K} 4 \mathrm{me} 3$ and $\mathrm{H} 3 \mathrm{~K} 36 \mathrm{me} 3$ as well as repressive marks $\mathrm{H} 3 \mathrm{~K} 9 \mathrm{me} 3, \mathrm{H} 3 \mathrm{~K} 27 \mathrm{me} 3$ and H4K20me3 [17]. Recently, this SILAC technology has been further developed to screen for PTM readers in the context of nucleosomes [18].

In summary, chemically modified histone peptides were used to identify almost all PTM readers so far. Weak interactions between PTM reading domains and short peptides likely reduce the dynamic range of such assays [8], thus neglecting potential PTM binders that prefer a nucleosomal context. Future screens utilizing native complexes in combination with modified nucleosomes should provide additional avenues to discover PTM readers.

\section{Reading modules of histone modications}

We will first discuss individual domains that recognize a unique PTM signal or, in a less stringent way, a bunch of similar signals. Without considering the role of DNA and chromatin context, interactions between modified histone peptides and recognition domains are similar to generic protein-protein interactions. Readers typically provide an accessible surface (such as a cavity or surface groove) to accommodate a modified histone residue, and determine the modification (acetylation vs methylation) or state specificity (such as mono- vs trimethylation of lysine). Readers also interact with the flanking sequence of the modified amino acid in order to distinguish sequence context. In this section, we will introduce the reading modules of individual PTM signals from a structural perspective. Although the folding of individual domains is critical for complex assembly and other functions, it is beyond the scope of this review. For simplicity, we concentrate on the interface that recognizes modified histones, particularly for figure illustrations.

\section{Lysine acetylation}

Although histone acetylation takes place at multiple lysines, genetic experiments suggest that many acetylation marks display redundant functions $[19,20]$. In addition, most acetylation writers and erasers - HATs and histone deacetylases (HDACs) - modify several lysines, and multiple enzymes target common sites [21]. Therefore, it was proposed that histone acetylation may function through cumulative effects [20].

Acetylated lysines (AcKs) can be recognized by bromo domains [10] and the tandem PHD domain [22, 23]. Many bromo domains use a narrow but deep cavity to accommodate acetyl-lysine and its long side-chain $[10,24]$ (Figure 1A). The bromo domain 1 of Brdt has a much wider pocket, which holds two AcKs simultaneously (Figure 1B) [25]; whereas the tandem PHD has a shallow cage [23]. All known AcK binding pockets are hydrophobic with hydrogen bond capacity at the bottom. AcK intercalates into the pocket mainly through a hydrogen bond and the interaction is stabilized by a network of water-mediated intermolecular hydrogen bonds [23].

Many bromo domains bind to multiple acetylated histones and the tandem PHD domain of human DPF3b also prefers acetylated $\mathrm{H} 3$ and $\mathrm{H} 4$ [22], indicating the lack of unique sequence recognition by these readers. This lim- 

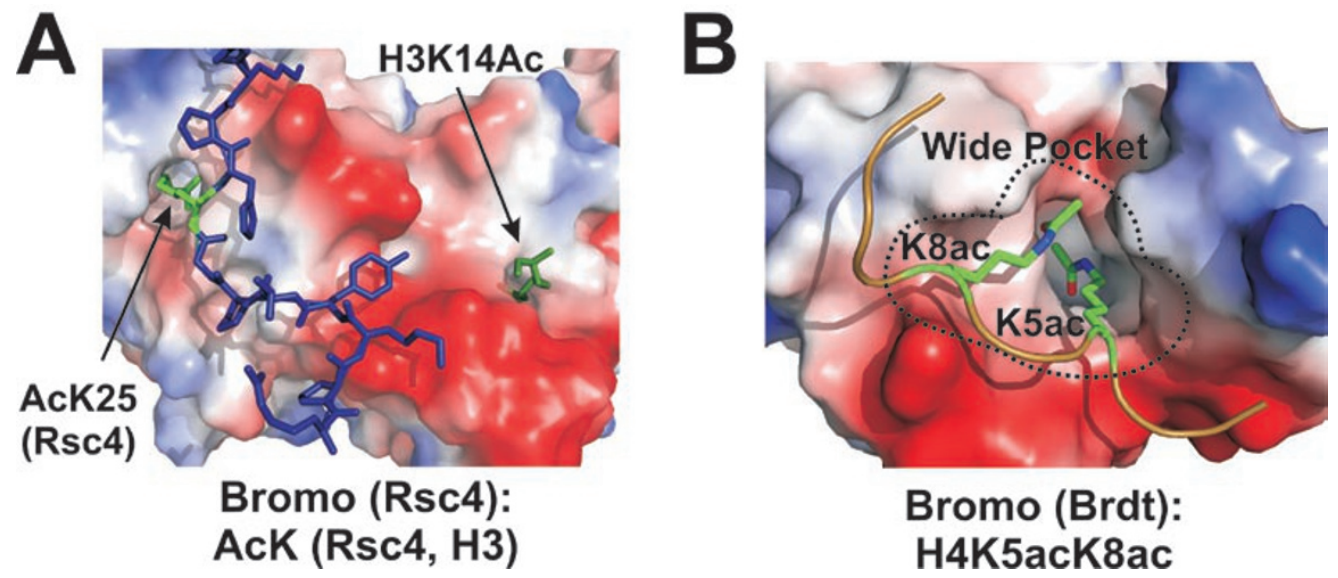

Figure 1 Readers for acetylated lysines (AcK). Protein domains are illustrated in surface representations of electrostatic potential and histone peptides are depicted in stick structure or cartoons with target lysines labeled in green. (A) Recognition of AcK by the bromo domains of Rsc4 (PDB 2R10). H3K14ac (from 2R0Y) is superimposed on 2R10 using DaliLite. (B) Structure of the bromo domain BD1 of BRDT bound to H4K5acK8ac (PDB 2WP2).

ited specificity is likely because the flanking peptides of AcK tend to make less defined contacts with the surface of the readers (Figure 1A). Since the interaction between AcK and its readers is relatively weak, multiple domains working in tandem are common. For instance, the chromatin-remodeling complex, RSC, has three bromo domain-containing subunits (Rsc1, Rsc2 and Rsc4) [26], the SAGA-HAT complex contains two-bromo domain proteins (Gen5 and Spt7) and the polybromo (PB) protein alone consists of six-bromo domains [27]. Multiple copies of readers also favor cumulative effects of histone acetylation.

\section{Lysine methylation}

Lysine methylation is one of the most stable histone marks, and it presents four types of signals: unmethylated (me0), mono- (me1), di- (me2) and tri- (me3) methylation. We include unmethylated lysine here as a part of the MeK-signaling group because methylation is the only known PTM at those residues and almost all known me 0 readers are sensitive to addition of methyl group on the lysine. Thus, we consider them bona fide sensors for MeK. Domains that recognize histone MeK include PHD, chromo, WD40, Tudor, double/tandem Tudor, MBT, Ankyrin Repeats, zf-CW and PWWP domains (Table 1), a long list that may continue to grow in coming years. Although different binders are folded differently to fulfill other structural requirements, for the domains that recognize the same mark, their binding surfaces remarkably resemble each other (such as in Figure 2A and $2 \mathrm{~B}$ ). Unlike acetylation, methylation is highly sitespecific and is maintained by histone methyltransferases and demethylases that possess stronger site-specificity than HAT and HDAC [28]. Due to the diversity of both methyl lysine signals and their recognition modules, instead of breaking down each family of recognition domains, we will generalize some common themes shared by multiple MeK binders and highlight a few representative examples.

Binding pockets Most MeK binders form an aromatic cage to accommodate MeK with its long hydrophobic side-chain. Primary functions of these pockets are to discriminate different PTMs and methylation states. MeKbinding pockets are relatively static on histone binding - an exception being the WD40 domain of EED, which will be discussed later. Binders for mono- and dimethylation tend to have a small keyhole-like cavity (Figure 2C) that limits the access of the larger trimethyl group. In contrast, binders for di- and trimethylation often use a wider and more accessible surface groove as binding pockets (Figure 2A, 2B and 2F and Figure 3), which may also result in less stringency for the specific methylation states.

Binding pockets for MeK can be loosely defined either as half aromatic cages (Figure 2D II and III) or as full aromatic cages (Figure 2D IV and V), based on the number of aromatic residues within the pocket. All residues within the pocket engage in binding with $\mathrm{MeK}$, as a point mutation of any residue severely compromises the substrate-binding ability $[8,29]$. Tri- and dimethylated ammonium groups were secured mostly through van der Waals and cation- $\pi$ interactions. Although no evidence suggests that the number of aromatic residues correlates 
Table 1 Readers of histone modifications

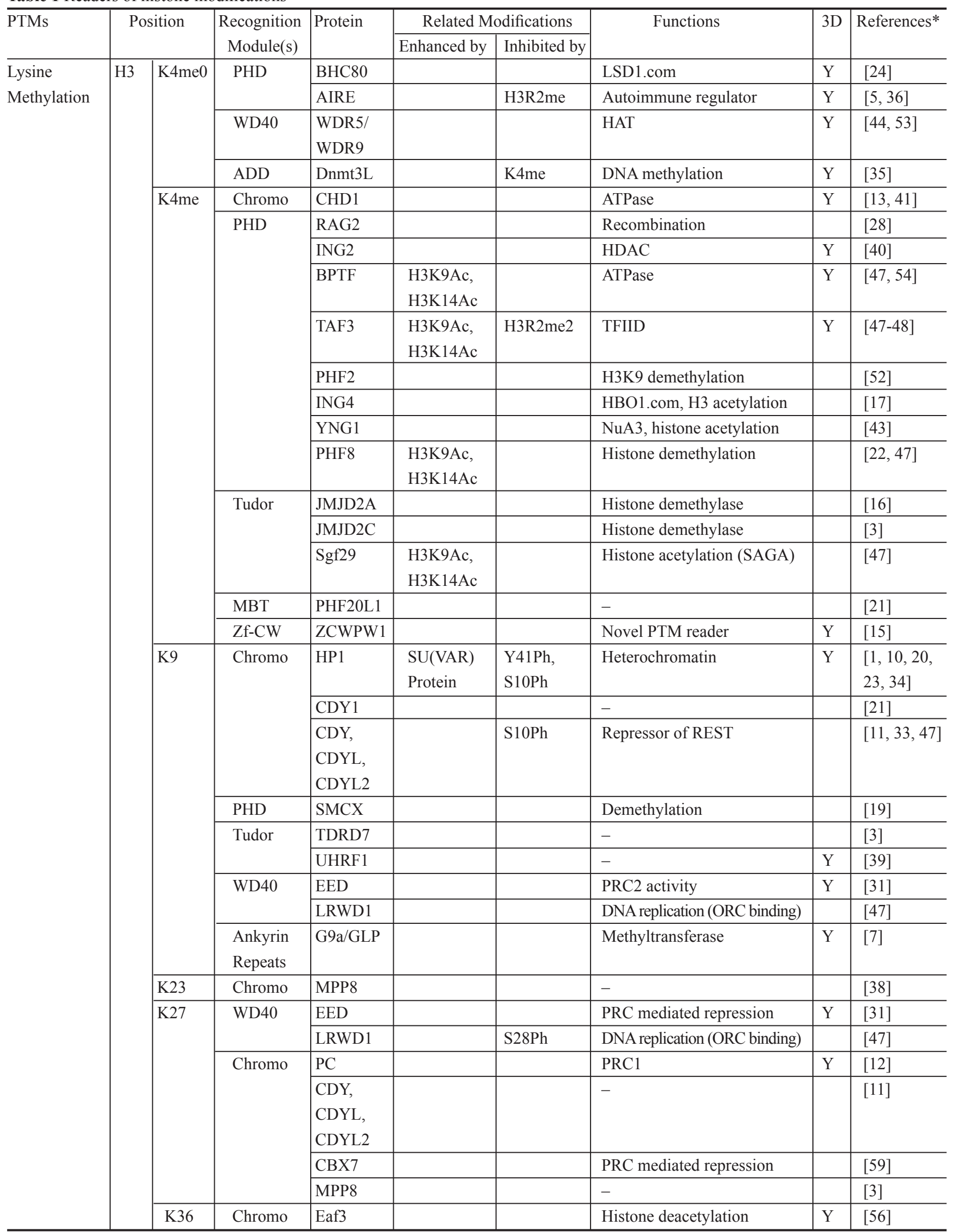


Table 1 Readers of histone modifications (continued)

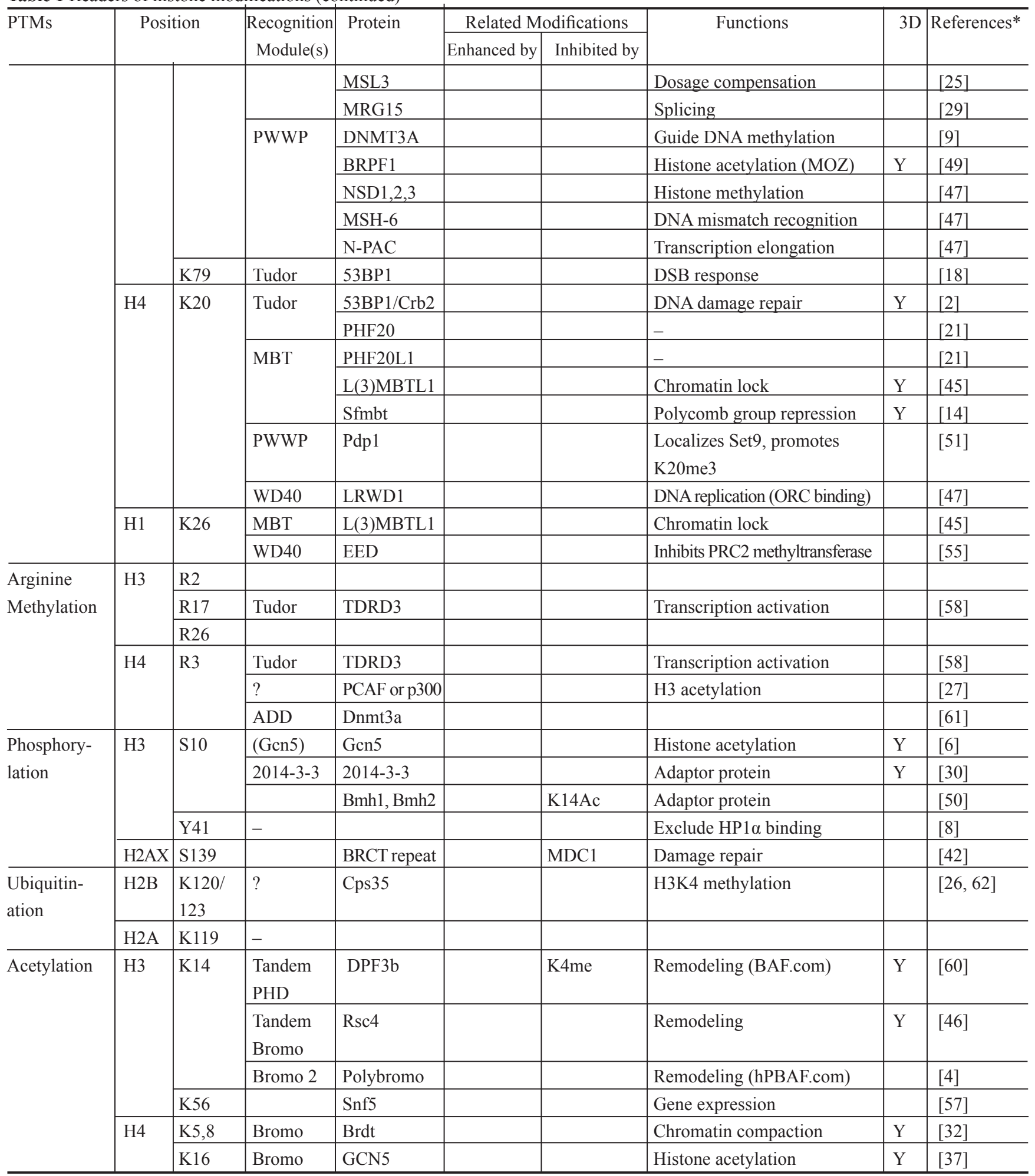

References for Table 1: 1.Nature (2001) V410,120-124; 2.Cell (2006) V127,1361-1373; 3.PLoS One (2009) V4,e6789; 4.Cell Res (2010) V20,529-538; 5.Nucleic Acids Res (2009) V37,2951-2961; 6.Mol Cell (2003) V12,461-473; 7.Nat Struct Mol Biol (2008) V15,245-250; 8.Nature (2009) V461,819-822; 9.J Biol Chem (2010) V285,26114-26120; 10.Mol Cell Biol (2007) V27,453-465; 11.J Biol Chem (2008) V283,1962619635; 12.Genes Dev (2003) V17,1870-1881; 13.Nature (2005) V438,1181-1185; 14.EMBO J (2009) V28,1965-1977; 15.Structure (2010) V18,1127-1139; 16.Science (2006) V312,748-751; 17.Mol Cell (2009) V33,248-256; 18.Nature (2004) V432,406-411; 19.Cell (2007) V128,10771088; 20.Science (2002) V295,2080-2083; 21.EMBO Rep (2006) V7,397-403; 22.Mol Cell (2010) V38,165-178; 23.Nature (2001) V410,116120; 24.Nature (2007) V448,718-722; 25.Mol Cell (2007) V28,121-133; 26.Cell (2007) V131,1084-1096; 27.Blood (2010) V115,2028-2037; 28.Immunity (2007) V27,561-571; 29.Science (2010) V327,996-1000; 30.Mol Cell (2005) V20,199-211; 31.Nature (2009) V461,762-767; 32.Na- 

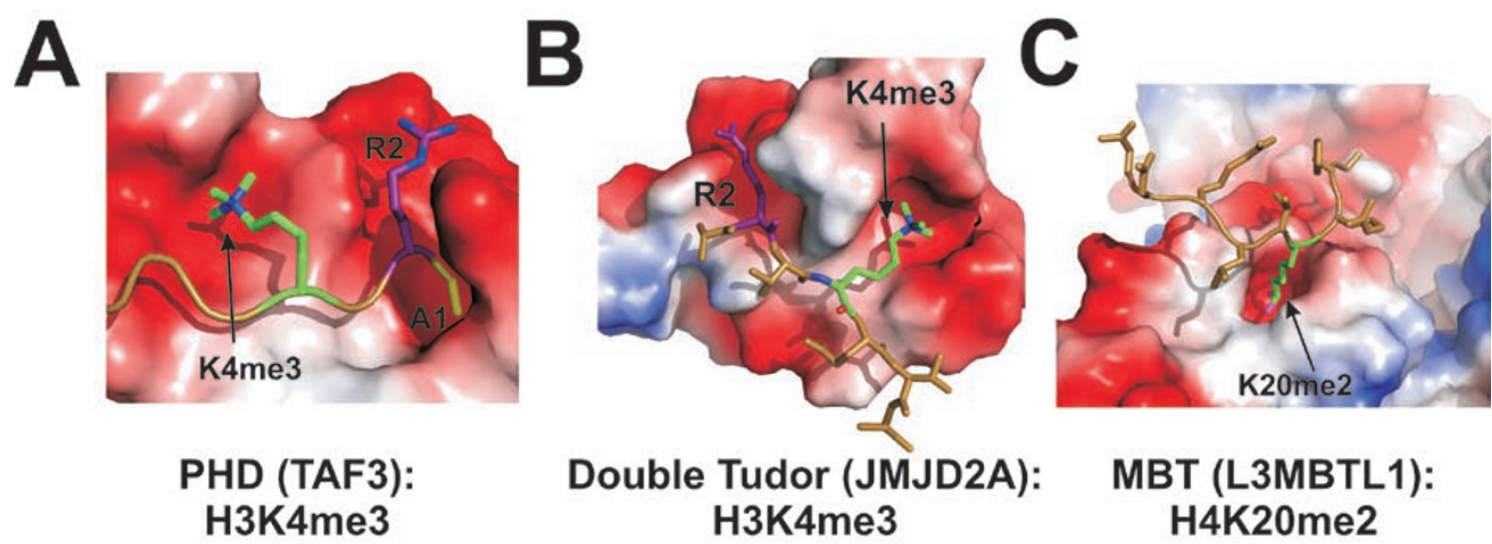

MBT (L3MBTL1): H4K20me2
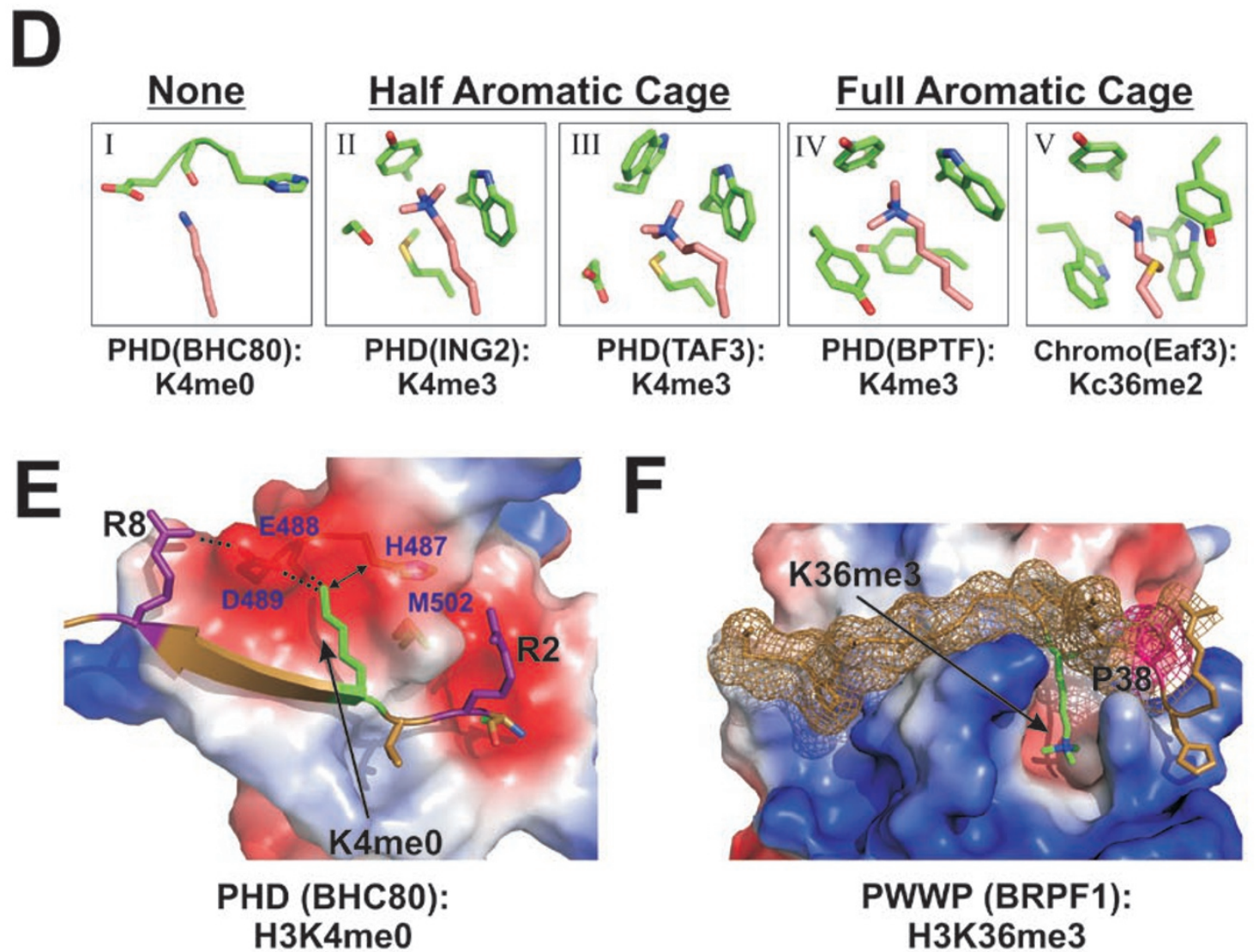

Figure 2 Readers for methylated lysines. Unless specified otherwise, color coding is similar to Figure 1 except that flanking arginines were labeled in purple. (A) Recognition of H3K4me3 by TAF3-PHD (PDB 2K17). (B) Recognition of H3K4me3 by the double-Tudor domain of JMJD2A (PDB 2GFA). (C) L3MBTL1 MBT bound to H4K20me2 (PDB 2PQW). (D) Comparison of binding surfaces from different MeK readers. Lysines are labeled in brown and pocket-forming residues are labeled in green (PDB 2PUY, 2G6Q, 2K17, 2F6J and 2K3Y). (E) Recognition of H3K4me0 by BHC80 PHD (PDB 2PUY). (F) Recognition H3K36me3 by the PWWP domain of Brpf1 (PDB 2X4X).

ture (2009) V461,664-668; 33.Mol Cell (2008) V32,718-726; 34.Nature (2002) V416,103-107; 35.Nature (2007) V448,714-717; 36.EMBO Rep (2008) V9,370-376; 37.EMBO J (2000) V19,6141-6149; 38.Nucleic Acids Res (2010) V38,e11; 39.Nucleic Acids Res (2010) V38,1796-1804; 40.Nature (2006) V442,96-99; 41.J Biol Chem (2005) V280,41789-41792; 42.Cell (2005) V123,1213-1226; 43.Mol Cell (2006) V24,785-796; 44.Nat Struct Mol Biol (2009) V16,678-680; 45.Cell (2007) V129,915-928; 46.Mol Cell (2007) V27,817-828; 47.Cell (2010) V142,967980; 48.Cell (2007) V131,58-69; 49.Nat Struct Mol Biol (2010) V17,617-619; 50.Mol Cell Biol (2008) V28,2840-2849; 51.Mol Cell (2009) V33,428-437; 52.J Biol Chem (2010) V285,9322-9326; 53.Cell (2005) V121,859-872; 54.Nature (2006) V442,86-90; 55.Proc Natl Acad Sci U S A (2010) V 56.Structure (2008) V16,1740-1750; 57.Cell (2005) V121,375-385; 58.Mol Cell (2010) V40,1016-1023; 59.Mol Cell (2010) V38,662-674; 60.Nature (2010) V466,258-262; 61.Nat Struct Mol Biol (2009) V16,304-311; 62.Mol Cell Biol (2010) V30,3635-3645; Notes: $\mathrm{Y}$ in the " $3 \mathrm{D}$ " column represents that the corresponding 3-D structure has been solved. 
with the binding capacity of MeK and the overall affinity to histone peptides, there is an example in which the tryptophan residue seems to generate a stronger cation- $\pi$ interaction than the tyrosine in a mutant protein (W868Y) [30]. This result implies that the tryptophan at the orthogonal position of MeK (Figure 2D III) contributes to a stronger binding pocket than the corresponding tyrosines in other aromatic cages (Figure 2D II, IV and V).

Unmethylated lysine (UmK) readers do not have apparent pockets (Figure 2D I and 2E). On reader binding, $\mathrm{UmK}$ is stabilized by intermolecular hydrogen bonds (e.g., in BHC80 PHD, the bonds between the epsilon amino group of H3K4 and D489 or E488 of PHD, Figure 2E). However, addition of a methyl group would clash with the binding surface [31]. This spatial restriction also specifies recognition of $\mathrm{UmK}$ by other $\mathrm{K} 4 \mathrm{me} 0$ readers, such as the ADD domain of Dnmt3L [32] and the PHD domain of AIRE [33].

The recognition of methyl states can be utilized in two ways. At some lysines, different methyl-states recruit different sets of effectors. For instance, Pdp1 binds to H4K20me1 for cell-cycle regulation, whereas Crb2 recognizes H4K20me2 to control a DNA damage checkpoint [34]. However, at other sites, methyl states only control the binding strength of the same chromatin regulators. For example, Rpd3S binds to K36me1 nucleosomes at a similar affinity to the unmodified ones, K36me2 shows stronger binding and K36me3 displays the highest affinity [35].

Flanking sequence interactions Readers of MeK make multiple contacts with flanking amino acids to determine the sequence context. Free histone peptides are normally unstructured in solution. However, on binding, they are induced into a $\beta$-sheet conformation, which is aligned antiparallel to the surface groove of the readers (Figure $2 \mathrm{E})$. This pairing interaction not only increases the overall affinity but also projects $\mathrm{MeK}$ in a specific orientation to influence its pocket binding (Figure 2E and 2F).

Flanking-sequence contacts can make MeK binders highly selective for the sequence context. For example, all three H3K4 readers shown in Figure 2A, 2B and 2E adopt a similar surface where H3R2 and H3K4 are divided into two separate binding pockets. H3R2 contributes significantly to the binding of TAF3 PHD (Figure 2A) and the JMJD2A double-Tudor domain (Figure 2B) but not for BHC80 PHD (where H3R8 plays a similar role by interacting with D489; Figure 2E). In contrast,
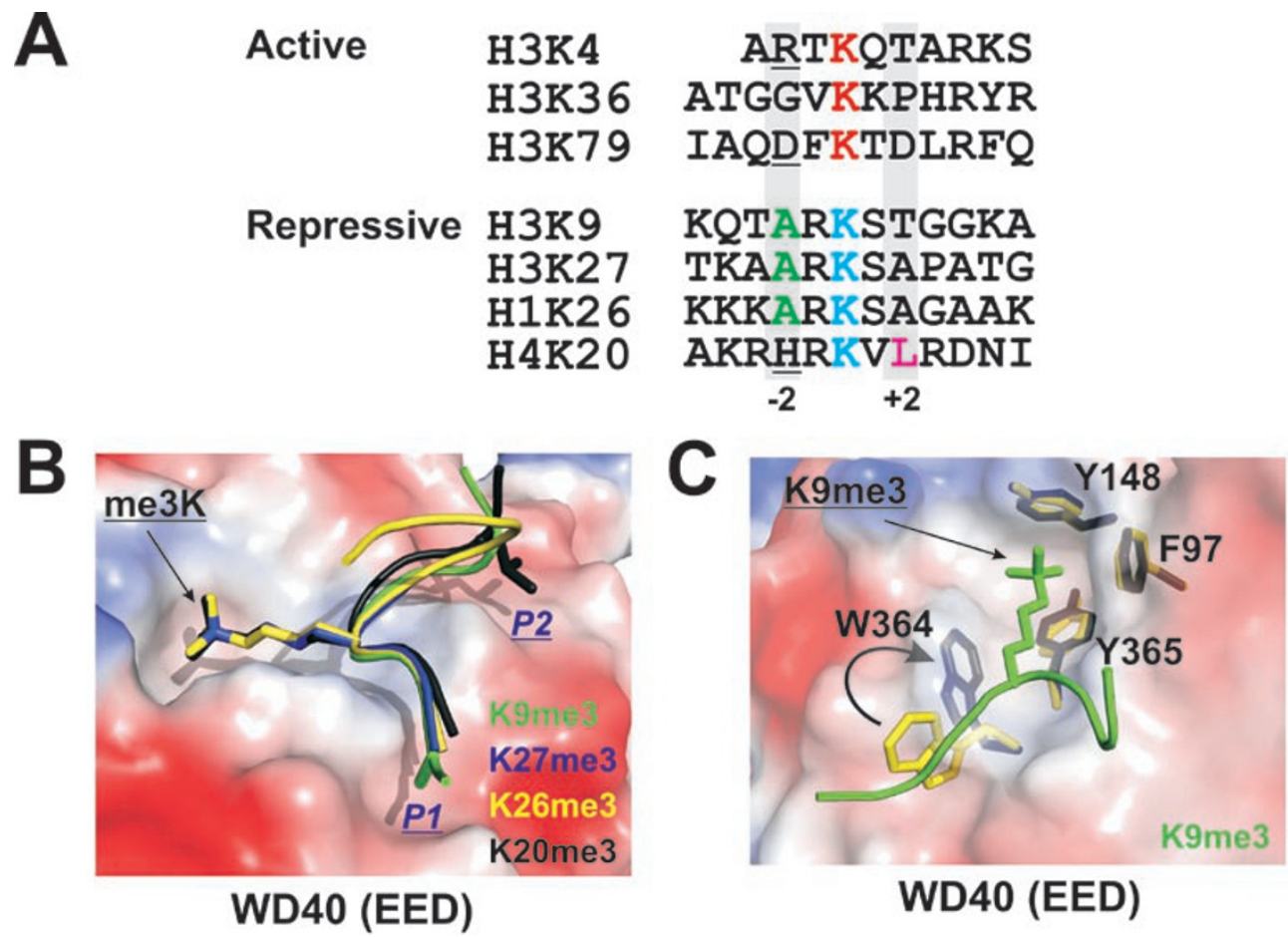

Figure 3 Recognition of methyl-lysines by the WD40 domain of EED. (A) Sequence of histone peptides. (B) Superposition of the binding of histone peptides to EED using DaliLite (PDB 3K27, 3JZG, 3IIY and 3JPX). (C) Superposition of the apo-EED (yellow) and EED bound to K9me3 (black) (PDB 3K27 and 3JZN). 
flanking-sequence interaction enables the WD40 domain of EED to broadly recognize a group of similar histone modifications $[36,37]$. EED has two small hydrophobic pockets (labeled as P1 and P2 in Figure 3B), which only accommodate small residues at the -2 or +2 position (Figure 3A) relative to MeK. This feature eliminates the binding of histone peptides that have bulky residues at these positions - such as the three active histone marks shown in Figure 3A. In contrast, it favors the binding of repressive mark histone peptides in which either an alanine is present at the -2 position or a leucine is at the +2 position (H4K20) [36, 37]. Lastly, MeK binders that do not make extensive contacts with the flanking sequence display a promiscuous PTM recognition pattern - such as the MBT domain of L3MBTL1, which binds to multiple lysines in the me1 or me2 states [38].

Histone end effects MeK that locates near the end of a histone peptide is easy to read. This is because: (1) the histone termini can be buried into a pocket, which greatly contributes to the overall affinity (Figure 2A, 2B and $2 \mathrm{E}$ ) and (2) without interference from adjacent peptide extension, the histone peptides can be fit into a variety of conformations, thus attracting more readers. A good example is the H3K4 methylation, which has strong and very well-studied reading modules.

In summary, it is the combination of the above three elements that determines the strength and specificity of a particular MeK reader. For instance, the PHD domain of TAF3 possesses a superior aromatic cage in which a tryptophan is at the base (Figure 2D III), as discussed above, $\mathrm{H} 3 \mathrm{~A} 1$ is buried in a deeper pocket than in JMJD2A (Figure 2B) or BHC80 (Figure 2E) and lastly, H3R2 interacts with a more negatively charged surface [30]. These fea- tures collectively make TAF3 PHD one of the strongest binders among known PTM readers.

\section{Arginine methylation}

Methylarginines (MeR) are found in three different forms: monomethylation (me1), symmetrical dimethylation (me2s) and asymmetrical dimethylation (me2a). Although arginine methylation has been linked to transcription for years, the readers of this mark were only reported recently. The ADD domain (containing a PHD motif) of the DNA methyltransferase Dnmt3a recognizes H4R3me2s but not H4R3me2a, thereby linking histone MeR to DNA methylation and gene repression [39]. The Tudor domain of TDRD3 is a reader for H3R 17me2a and H4R3me2a [40]. TDRD3 acts as a transcription coactivator and is enriched at transcription start sites [40], which link MeR to active transcription.

Due to limited information about MeR readers, it is too early to evaluate their state specificity and sequence fidelity in general. However, the ADD domain clearly discriminates the symmetry of MeR [39]. In yeast, H3R2me 1 and H3R2me2 display distinct localization patterns and transcriptional outputs. H3R2me1 is linked to activation while H3R2me2 is involved with repression [41], suggesting that MeR readers are likely specific to methyl states.

\section{Serine phosphorylation}

Protein domains that recognize phosphorylated amino acids in a non-histone context are well characterized and include SH2, BRCT, WW, FHA, WD40, 14-3-3 and LRR domains. However, only two readers have been identified for phosphorylated serine $(\mathrm{PhS})$ in histones. The BRCT domain of MDC1 binds to $\mathrm{PhS}$ near the $\mathrm{C}$-terminus of
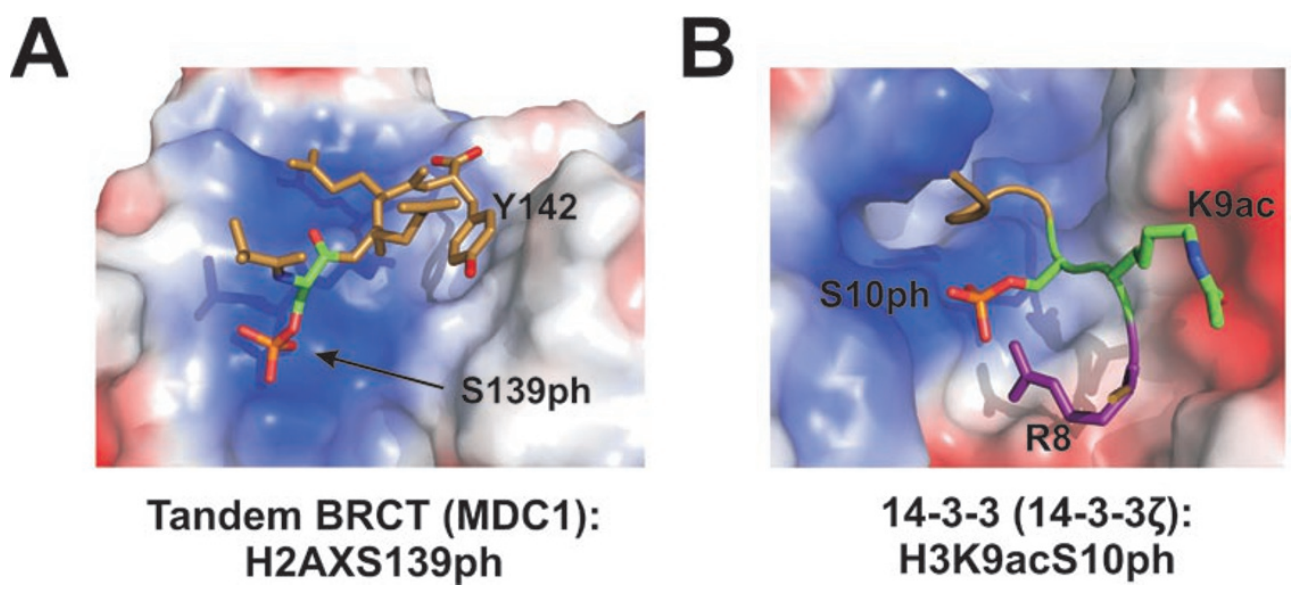

Figure 4 Readers for phosphorylated serines. (A) The BRCT domain of MDC1 binds to $\gamma \mathrm{H} 2 \mathrm{AX}$ (PDB 2AZM). (B) Recognition of H3K9acS10ph by14-3-3 (PDB 2C1J). 

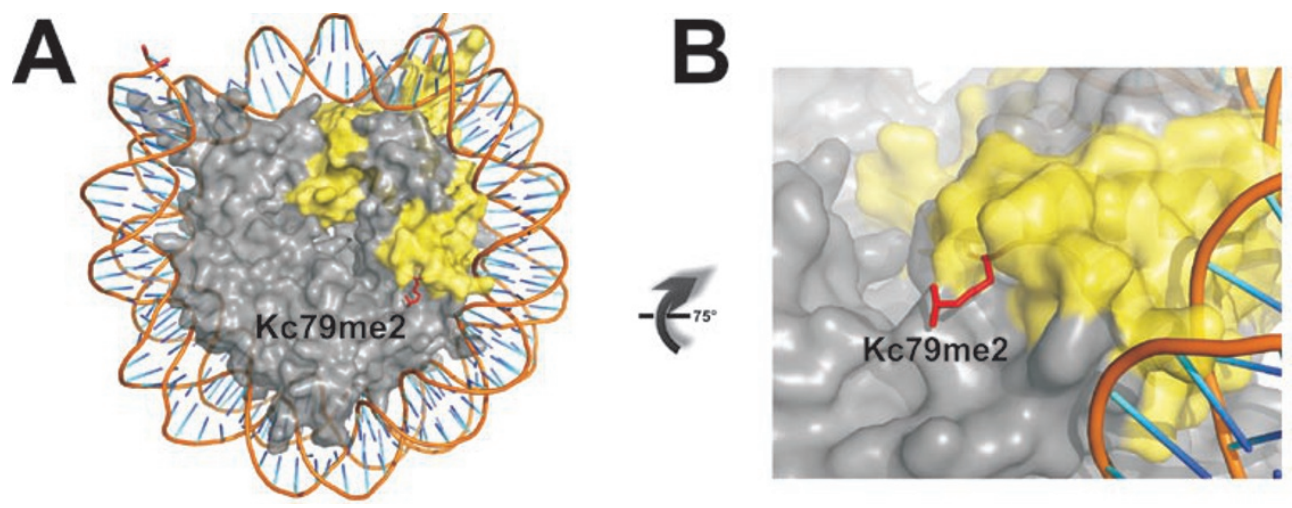

Figure 5 Structure of K79me nucleosomes. Histone H3 is labeled in yellow (PDB 3C1C).

histone H2AX [15]. The PhS peptide docks at the interbridge between two lobes of BRCT (Figure 4A). PhS is stabilized by several hydrogen bonds. The C-terminus of the peptide is anchored by a surface pocket to provide additional affinity [15]. Curiously, phosphorylation of the H2AX family typically takes place at a conserved SQ(E/ D)X motif [42]. However, the glutamine does not appear to be important for BRCT contact (Figure 4A).

$\mathrm{PhS}$ is also read by the 14-3-3 family. Mammalian 143-3 $\zeta$ recognizes $\mathrm{H} 3 \mathrm{~S} 10 \mathrm{ph}$ peptide using a deep scaffold (Figure 4B) [43]. PhS is secured through multiple hydrogen bonds and $\mathrm{H} 3 \mathrm{~K} 9 \mathrm{ac}$ does not disrupt peptide contacts due to a large binding surface (Figure 4B). Thus, it was concluded that $\mathrm{H} 3 \mathrm{~K} 9 \mathrm{ac}$ does not influence the binding of 14-3-3 to $\mathrm{PhS}$ [43]. Interestingly, the binding of the yeast 14-3-3 proteins Bmh1 and Bmh2 to $\mathrm{H} 3 \mathrm{~S} 10$ ph peptides is stimulated by $\mathrm{H} 3 \mathrm{~K} 14 \mathrm{ac}$, and $\mathrm{H} 3 \mathrm{~K} 14 \mathrm{ac}$ is important for the recruitment of Bmh1 in vivo [44]. Future structural analysis would provide more insight into how the same family of readers responds differently to the PTM near its primary target.

\section{Lysine ubiquitination}

No histone ubiquitination reading module has been clearly identified yet. Unlike other PTMs, the ubiquitin (Ub) moiety is relatively large in size. Typical Ub binders recognize either the surface of $\mathrm{Ub}$ (such as the hydrophobic patch) or the C-terminal region where $\mathrm{Ub}$ is conjugated to target proteins [45]. Thus, finding specific readers for ubiquitinated histones has proven to be difficult. A recent discovery that histones can be mono-ubiquinated and poly-ubiquitinated [46] has further complicated the search for readers. However, one potential candidate has emerged from a study showing that incorporation of the Cps35 subunit into a histone methyltransferase complex, COMPASS, depends on ubiquitination of H2B [47]. This result implied that Cps35 may be the direct reader of $\mathrm{H} 2 \mathrm{BUb}$ or may associate with a specific reader, a notion confirmed by another study using a H2B ubiquitinationdefective mutant [48].

\section{Chromatin context}

Under physiological conditions where modified histones are embedded in chromatin, PTM signals might be presented differently than in free peptides. For example, once wrapped in a nucleosome, K79me2 appears to be less accessible (Figure 5) [49]. Given this structural constraint, the flanking sequence of K79me 2 could not be freely changed into a conformation that favors the binding of readers, and neighboring residues of $\mathrm{H} 3 \mathrm{~K} 79$ are not fully exposed. Therefore, it is important to examine PTM recognition by reading modules in a more relevant chromatin context in the future.

\section{Reading modes}

Chromatin-associated complexes typically contain multiple PTM readers to respond to different signals. Here, we will discuss how each individual reading module coordinately contributes to the targeting of a complex to modified chromatin.

\section{Monovalent recognition - "one domain-one mark"}

Based on pairings of PTM and their corresponding reading modules, it was assumed that a single domain/ PTM interaction can direct a complex to its genome targets because mutation of either PTM sites or recognition domains disrupts the proper recruitment of the complex. However, accumulating evidence suggests that this one domain-one mark mechanism might not be sufficient to decipher the complex PTM language in a cellular environment. First, one PTM can be recognized by several 
readers (e.g., H3K4me alone has eight different readers, Table 1). Second, complexes carrying out opposite reactions can share the same binding motif (e.g., the chromo domain-containing Eaf3 is the subunit of histone acetyltransferase NuA4 and histone deacetylase Rpd3S [1]). Third, a single domain reads several PTMs (e.g., LRWD1 within the origin recognition complex (ORC) recognizes K9me3, K27me3 and K20me3 [17]).

\section{Multivalent recognition}

Since chromatin complexes tend to contain several PTM reading modules, multivalent binding has emerged as a prevalent theme for recognizing modified chromatin. Combinations of multiple weak interactions not only can enhance overall binding through cooperation but also allow fine-tuned regulation of individual contacts so as to sense subtle environmental cues. We will divide our discussion into four categories. However, these mechanisms are not mutually exclusive and can be further combined.

Targets within one histone The TAF1 subunit of TFIID was first reported to utilize double-bromo domains to recognize the dual-acetylated histone peptide, H4K5acK12ac [11]. Interestingly, TFIID also binds to H3K4me3 peptides (recognized by TAF3 PHD) more strongly when it is flanked by H3K9acK14ac [17], suggesting additional synergy between the PHD and bromo domains. Similarly, the HAT-SAGA complex employs the double Tudor of the Sgf29 subunit (which binds to K4me3) and the bromo domain of Gen5 or Spt7 (which recognizes H3K9ac14ac) to preferentially target peptides carrying combined PTM [17].

Targets within one nucleosome Multivalent recognition is more advantageous for native complexes to recognize modified nucleosomes. The chromo domain of Eaf3 is a weak K36me reader [50]. Although Eaf3 is a subunit of both NuA4 and Rpd3S, only Rpd3S binds to K36-methylated nucleosomes [51], suggesting that monovalent recognition is not sufficient. Indeed, Rpd3S uses another reading module, the PHD domain of Rco1, in combination with the chromo domain of Eaf3 to achieve recognition of K36me in the chromatin context [51]. Likewise, the binding of the PRC2 complex to nucleosomes depends on multiple contacts: the WD40 domain of the EED subunit binds to methylated histones (Figure 3); the N-terminus of EED interacts with histone $\mathrm{H} 3$ and the RbAp48 subunit binds to histone H4 [52]. However, it is not clear how these three independent contacts cooperatively lead to the binding of PRC2 to the nucleosomes.

Targets within multiple nucleosomes Multivalent rec- ognition is also utilized by complexes to interact with an array of nucleosomes. (1) The SIR complex binds to trinucleosomal templates through at least three contact points: Sir4 binds to DNA; Sir3 binds to the unmodified histone $\mathrm{H} 4$ tail; and Sir3 binds to histone $\mathrm{H} 3$, which is sensitive to H3K79 methylation [53]. (2) PRC1 mediates chromatin compaction through its PSC subunit in a histone-tail-independent manner [54], while the chromo domain of the Pc subunit binds to H3K27-methylated histone tails. However, whether both contacts are important for PRC1 in vivo targeting remains to be tested. (3) The DNA methyltransferase, Dnmt3b, preferentially binds to highly compacted and hypoacetylated long nucleosomal arrays [55], suggesting that its targets likely reside in different nucleosomal surfaces. (4) Three MBT domains of L3MBTL1 can bind to at least two nucleosomes simultaneously through the MBT/MeK interaction discussed above [38]. Therefore, it is possible that L3MBTL1 brings two distant nucleosomes together - even when they are on different chromosomes.

\section{Recognition of specific DNA sequence and histone} PTM Although most chromatin factors bind to nucleosomes regardless of underlying DNA sequence, some complexes possess sequence-recognition ability. Besides having two PTM readers (TAF3/PHD and TAF1/bromo), TFIID also contains the TBP subunit that recognizes the TATA box and is important for TFIID template engagement [1]. The Rpd3L complex also has this combinatorial recognition potential because of the Pho23 subunit, which contains a K4me3-reading PHD domain and the Ume6/Ash1 subunits, both of which are sequence-specific DNA-binding proteins [56]. Recently, the histone demethylase, KDM2A, was shown to recognize methylated DNA [57], and it also contains a potential PTMreading PHD domain.

\section{Regulation of reading histone modications}

Chromatin complexes possess intrinsic properties to recognize certain PTM. However, this recognition can be regulated at two levels: modification of the reading unit or adjustment of the signal platform.

\section{Regulation of the readers}

By RNA Non-coding RNA (ncRNA) plays important roles in targeting chromatin regulators to their cognate sites. The CBX7 subunit of the PRC1 complex not only contains a chromo domain that reads $\mathrm{K} 27 \mathrm{me} 2$, but also recognizes an antisense ncRNA transcribed from the INK $4 \mathrm{~b} / \mathrm{ARF} / \mathrm{INK} 4 \mathrm{a}$ locus using a different binding surface [58]. ncRNA association is important for PRC1 
targeting and repression functions [58]. Similarly, short ncRNA generated from PRC2-repressed promoters forms stem-loop structures that interact with PRC2 and control its localization [59]. HOTAIR ncRNA and Xist RNA also help targeting PRC2 in cis $[60,61]$. In these cases, it is not clear how RNA binding coordinates with PTM recognition.

By binding partners $\mathrm{HP} 1$ reads $\mathrm{K} 9$ me through its chromo domain. However, it was found that ORC and HP1 are mutually required for each other to bind to K9methylated heterochromatin [62]. Moreover, the binding of HP1 to K9-methylated nucleosomes is stimulated by addition of the auxiliary factors ACF1 and SU(VAR)3-9 [63], underscoring the importance of binding partners for PTM recognition.

By conformational changes of the readers The tandem bromo domains of the Rsc4 subunit of the remodeling complex RSC are responsible for recognizing H3K14ac (second bromo domain - BD2; Figure 1A, right side) [24]. Interestingly, the first bromo domain also binds to acetylated $\mathrm{K} 25$ of Rsc4, which is sufficient to inhibit the binding of BD2 to $\mathrm{H} 3 \mathrm{~K} 14 \mathrm{ac}$, presumably due to steric hindrance [24]. This result manifests a novel auto-regulatory mechanism for PTM binding. In another example, one of four pocket-forming residues (W364) only rotates to the proper position when EED is bound by histone peptides, suggesting that the binding site for MeK is cryptic and a conformational change driven by histone peptide binding is required $[36,37]$.

\section{Regulation of the signal context}

By other modifications (histone modification crosstalk) The flanking sequences make important contributions to PTM reading, therefore, modification at adjacent residues could easily influence the binding of the readers. For instance, $\mathrm{H} 3 \mathrm{~S} 10 \mathrm{Ph}$ releases the binding of HP1 to K9me [64] and phosphorylation of H3T6 disrupts LSD1 binding to K4me [65]. As for K4me readers, H3R2 binds to a different pocket from H3K4 (Figure 2A and 2B). But steric hindrance caused by addition of methyl groups in MeR directly reduces the H3R2 binding, which in turn decreases overall affinity of K4-methylated peptides [30]. Another interesting case is that of $\mathrm{H} 3 \mathrm{~K} 4 \mathrm{ac}$, which differentially regulates two K9me readers - the Chp $1 / \mathrm{Clr} 4$ methyltransferase complex and the Chp2/Swi6 complex - thus tipping the balance of these two important heterochromatin regulators during different cell-cycle stages [66]. PTM recognition can also be regulated by histone modifications at distant residues. For instance, phospho- rylation of $\mathrm{H} 3 \mathrm{Y} 41$ inhibits $\mathrm{HP} 1 \alpha$ binding to $\mathrm{K} 9 \mathrm{me}$ [67]. However, secondary effectors might mediate such an effect in this case.

By chromatin context Although Crb2 (53BP1) recognizes H4K20me and H3K79me in vitro, those two marks are not accessible to $\mathrm{Crb} 2$ before DNA damage $[16,68]$. Therefore, changes of topological tension and/ or the high-order chromatin structure upon DNA damage are important for displaying those marks to downstream readers.

\section{Functional readouts of PTM}

The functional readouts of particular PTM are dictated by functions of the effectors/readers. We will categorize these readers into four groups (Figure 6).

\section{Chromatin architectural proteins}

Protein complexes that bind to multiple nucleosomes simultaneously have the potential to induce chromatin compaction or serve as physical shields to block access to underlying DNA. These so-called architectural proteins often spread across a large region through selfpropagation and oligomerization [69], such as the SIR complex (which targets hypoacetylated and H3K79-unmethylated regions) [53] and heterochromatin protein 1 (which binds to K9me) [12]. These architectural proteins can even remain bound to nucleosomes during DNA replication, such as the PRC1 complex [70].

\section{Chromatin remodelers}

Once targeted by PTM, chromatin remodeling complexes either make nucleosomal DNA more accessible or mobilize nucleosomes to different positions [4]. For instance, the remodeler, RSC, targets hyperacetylated nucleosomes at coding regions [71]. The BPTF subunit of NURF contains an H3K4me3-reading PHD domain and an AcK-reading bromo domain, both of which are important for NURF localization [72]. One unique feature of these readers is that they might not be enriched at their true targets because of a hit-and-run mode of action in which remodelers do not stay bound to the region after the reaction (e.g., the yeast Isw2 complex) [73].

\section{Chromatin modifiers}

Many primary PTMs do not have direct influence on chromatin structure except for recruiting secondary chromatin modifiers that can either modify or de-modify local chromatin. For instance, K36me3 functions by recruiting Rpd3S to deacetylate transcribed chromatin [50]. K20me1 is recognized by the PWWP domain of Pdp1, 


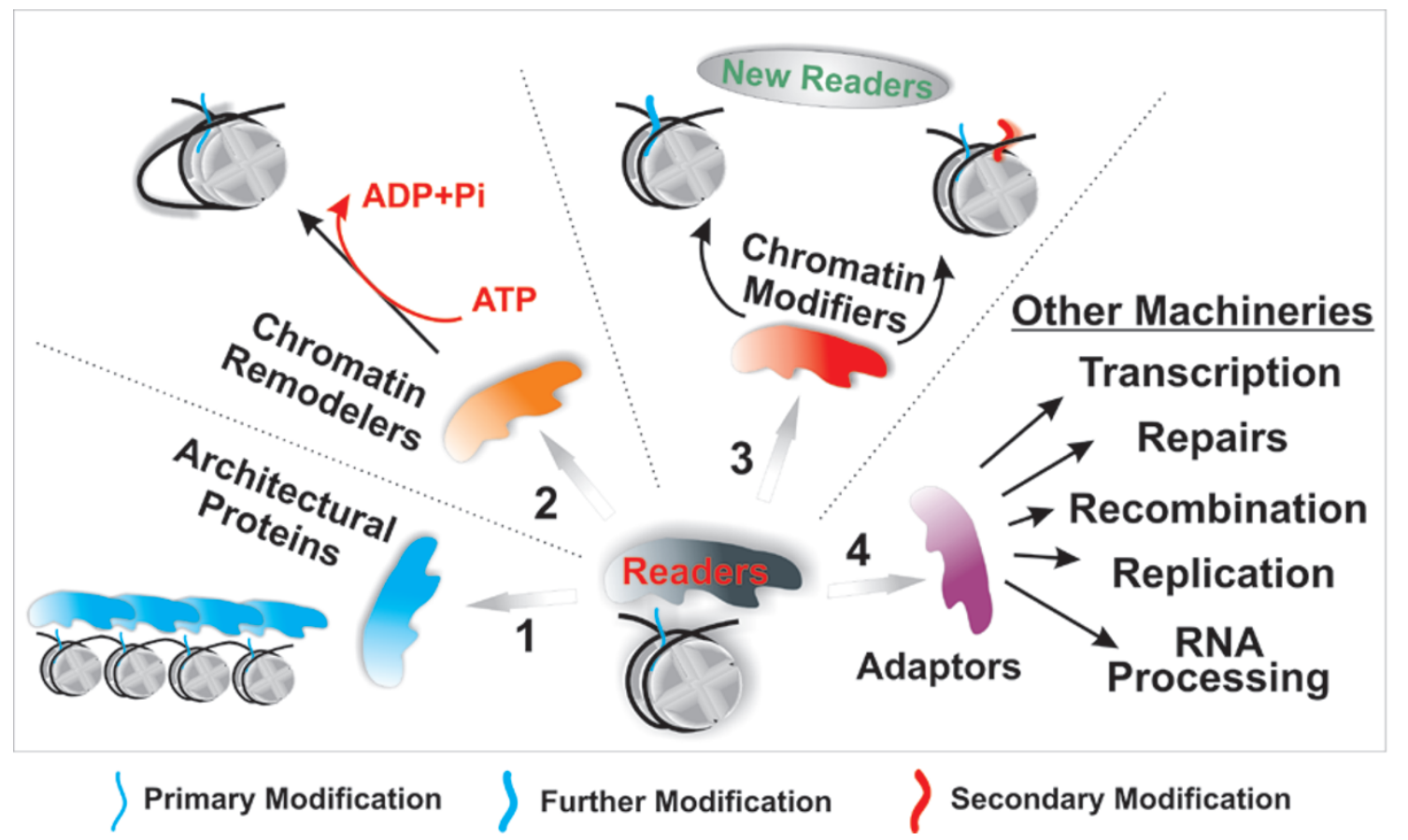

Figure 6 Models for the functional outcomes of reading modified histones.

thereby localizing the Set9 methyltransferase to convert $\mathrm{K} 20 \mathrm{me} 1$ into K20me3 [74]. KDM4a is guided by its Tudor domain to $\mathrm{H} 3 \mathrm{~K} 4 \mathrm{me} 3$ and $\mathrm{H} 4 \mathrm{~K} 20 \mathrm{me} 3$ regions to demethylate me 2 and me3 on K9 and K36 [75]. Moreover, PTM recognition also directs DNA modifiers. DNA methyltransferase, Dnmt3a, binds to K36me3 via its PWWP domain [76], and its partner, Dnmt3L, recognizes $\mathrm{K} 4 \mathrm{me} 0$ [32]. Given the overlapping pattern of these two marks, DNA methylation could be precisely guided by histone PTM.

\section{Recruitment of other machinery}

PTM readers can serve as adaptors to recruit factors that are directly involved in DNA metabolism activities.

Transcription: General transcription factor, TFIID, reads both AcK and $\mathrm{H} 3 \mathrm{~K} 4 \mathrm{me} 3$ signals [17].

DNA damage repair: MDC1 binds to phosphorylated H2AX near double-strand break (DSB)-flanking chromatin and subsequently activates a cascade of phosphorylation events that lead to the recruitment of histone-Ub ligase, RNF8. Histone ubiquitination then either acts to recruit repair machinery or somehow exposes H4K20me and $\mathrm{H} 3 \mathrm{~K} 79 \mathrm{me}$ for 53BP1 recruitment [77].

Recombination: Recombination-activating protein, RAG2, binds to $\mathrm{H} 3 \mathrm{~K} 4 \mathrm{me} 3$ at transcribed genes while RAG1 recognizes the recombination signal sequence. Neither of them is sufficient to initiate recombination; however, when these two signals overlap, RAG1 and
RAG2 multimerize to start recombination [78].

RNA processing: MRG15 recognizes K36me3 at transcribed regions via its chromo domain and recruits splicing regulator PTB to control alternative splicing [79].

Replication: Both PTM patterns and genome accessibility are important for replication timing [80, 81], implying that DNA replication machinery also has the capacity to recognize histone modifications. Recently, it is shown that an ORC-associated protein - LRWD1 recognizes both DNA methylation and histone modification, and is important for initiation of DNA replication $[17,18,82]$.

\section{Future directions}

Reading histone modification is a highly context-dependent process. A recent systematic protein-localization mapping reveals that the chromo domain-containing MRG15 is only recruited to a subset of K36me3-enriched genes [83], implying that there must be another unidentified essential recruiting signal. Therefore, a general challenge for the field is to identify the preferred PTM combinations for certain chromatin readers. In addition, little is known about readers that recognize PTM on histone globular domains. Future screens using modified nucleosomal arrays might provide useful insights in this regard. 


\section{Acknowledgments}

We are indebted to Dr Chun Ruan (UT Southwestern Medical Center) for her critical comments on the manuscript and Dr Carson Harrod (Baylor Institute for Immunology Research) for editorial assistance. We also thank Phi Luong (UT Southwestern Medical Center) for his help in preparing the figures. BL is a W.A. "Tex" Moncrief, Jr Scholar in Medical Research and supported by grants from the National Institutes of Health (R01GM090077), the Welch Foundation (I-1713), March of Dimes Foundation and the American Heart Association. JLW is supported by Stowers Institute for Medical Research.

\section{References}

1 Li B, Carey M, Workman JL. The role of chromatin during transcription. Cell 2007; 128:707-719.

2 Ahmad K, Henikoff S. Epigenetic consequences of nucleosome dynamics. Cell 2002; 111:281-284.

3 Kouzarides T. Chromatin modifications and their function. Cell 2007; 128:693-705.

4 Workman JL, Kingston RE. Alteration of nucleosome structure as a mechanism of transcriptional regulation. Annu Rev Biochem 1998; 67:545-579.

5 Shogren-Knaak M, Ishii H, Sun JM, Pazin MJ, Davie JR, Peterson CL. Histone H4-K16 acetylation controls chromatin structure and protein interactions. Science 2006; 311:844-847.

6 Jenuwein T, Allis CD. Translating the histone code. Science 2001; 293:1074-1080.

7 Strahl BD, Allis CD. The language of covalent histone modifications. Nature 2000; 403:41-45.

8 Taverna SD, Li H, Ruthenburg AJ, Allis CD, Patel DJ. How chromatin-binding modules interpret histone modifications: lessons from professional pocket pickers. Nat Struct Mol Biol 2007; 14:1025-1040.

9 Berger SL. The complex language of chromatin regulation during transcription. Nature 2007; 447:407-412.

10 Dhalluin C, Carlson JE, Zeng L, He C, Aggarwal AK, Zhou MM. Structure and ligand of a histone acetyltransferase bromodomain. Nature 1999; 399:491-496.

11 Jacobson RH, Ladurner AG, King DS, Tjian R. Structure and function of a human TAFII250 double bromodomain module. Science 2000; 288:1422-1425.

12 Bannister AJ, Zegerman P, Partridge JF, et al. Selective recognition of methylated lysine 9 on histone H3 by the HP1 chromo domain. Nature 2001; 410:120-124.

13 Kim J, Daniel J, Espejo A, et al. Tudor, MBT and chromo domains gauge the degree of lysine methylation. EMBO Rep 2006; 7:397-403.

14 Bua DJ, Kuo AJ, Cheung P, et al. Epigenome microarray platform for proteome-wide dissection of chromatin-signaling networks. PLoS One 2009; 4:e6789.

15 Stucki M, Clapperton JA, Mohammad D, Yaffe MB, Smerdon SJ, Jackson SP. MDC1 directly binds phosphorylated histone $\mathrm{H} 2 \mathrm{AX}$ to regulate cellular responses to DNA double-strand breaks. Cell 2005; 123:1213-1226.

16 Huyen Y, Zgheib O, Ditullio RA Jr, et al. Methylated lysine 79 of histone $\mathrm{H} 3$ targets 53BP1 to DNA double-strand breaks. Nature 2004; 432:406-411.
17 Vermeulen M, Eberl HC, Matarese F, et al. Quantitative interaction proteomics and genome-wide profiling of epigenetic histone marks and their readers. Cell 2010; 142:967-980.

18 Bartke T, Vermeulen M, Xhemalce B, Robson SC, Mann M, Kouzarides T. Nucleosome-interacting proteins regulated by DNA and histone methylation. Cell 2010; 143:470-484.

19 Shahbazian MD, Grunstein M. Functions of site-specific histone acetylation and deacetylation. Annu Rev Biochem 2007; 76:75-100.

20 Dion MF, Altschuler SJ, Wu LF, Rando OJ. Genomic characterization reveals a simple histone $\mathrm{H} 4$ acetylation code. Proc Natl Acad Sci USA 2005; 102:5501-5506.

21 Lee KK, Workman JL. Histone acetyltransferase complexes: one size doesn't fit all. Nat Rev Mol Cell Biol 2007; 8:284-295.

22 Lange M, Kaynak B, Forster UB, et al. Regulation of muscle development by DPF3, a novel histone acetylation and methylation reader of the BAF chromatin remodeling complex. Genes Dev 2008; 22:2370-2384.

23 Zeng L, Zhang Q, Li S, Plotnikov AN, Walsh MJ, Zhou MM. Mechanism and regulation of acetylated histone binding by the tandem PHD finger of DPF3b. Nature 2010; 466:258-262.

24 VanDemark AP, Kasten MM, Ferris E, Heroux A, Hill CP, Cairns BR. Autoregulation of the rsc4 tandem bromodomain by gen5 acetylation. Mol Cell 2007; 27:817-828.

25 Moriniere J, Rousseaux S, Steuerwald U, et al. Cooperative binding of two acetylation marks on a histone tail by a single bromodomain. Nature 2009; 461:664-668.

26 Cairns BR, Schlichter A, Erdjument-Bromage H, Tempst P, Kornberg RD, Winston F. Two functionally distinct forms of the RSC nucleosome-remodeling complex, containing essential AT hook, BAH, and bromodomains. Mol Cell 1999; 4:715723.

27 Charlop-Powers Z, Zeng L, Zhang Q, Zhou MM. Structural insights into selective histone $\mathrm{H} 3$ recognition by the human Polybromo bromodomain 2. Cell Res 2010; 20:529-538.

28 Tsukada Y, Fang J, Erdjument-Bromage H, et al. Histone demethylation by a family of JmjC domain-containing proteins. Nature 2006; 439:811-816.

29 Vermeulen M, Mulder KW, Denissov S, et al. Selective anchoring of TFIID to nucleosomes by trimethylation of histone H3 lysine 4. Cell 2007; 131:58-69.

30 van Ingen $\mathrm{H}$, van Schaik FMA, Wienk $\mathrm{H}$, et al. Structural insight into the recognition of the H3K4me3 mark by the TFIID subunit TAF3. Structure 2008; 16:1245-1256.

31 Lan F, Collins RE, De Cegli R, et al. Recognition of unmethylated histone $\mathrm{H} 3$ lysine 4 links BHC80 to LSD1-mediated gene repression. Nature 2007; 448:718-722.

32 Ooi SK, Qiu C, Bernstein E, et al. DNMT3L connects unmethylated lysine 4 of histone $\mathrm{H} 3$ to de novo methylation of DNA. Nature 2007; 448:714-717.

33 Org T, Chignola F, Hetenyi C, et al. The autoimmune regulator $\mathrm{PHD}$ finger binds to non-methylated histone $\mathrm{H} 3 \mathrm{~K} 4$ to activate gene expression. EMBO Rep 2008; 9:370-376.

34 Wang Y, Jia S. Degrees make all the difference: the multifunctionality of histone H4 lysine 20 methylation. Epigenetics 2009; 4:273-276.

35 Li B, Jackson J, Simon MD, et al. Histone H3 lysine 36 dimethylation (H3K36me2) is sufficient to recruit the Rpd3s histone deacetylase complex and to repress spurious transcription. 
J Biol Chem 2009; 284:7970-7976.

36 Margueron R, Justin N, Ohno K, et al. Role of the polycomb protein EED in the propagation of repressive histone marks. Nature 2009; 461:762-767.

$37 \mathrm{Xu} \mathrm{C}$, Bian C, Yang W, et al. Binding of different histone marks differentially regulates the activity and specificity of polycomb repressive complex 2 (PRC2). Proc Natl Acad Sci USA 2010; 107:19266-19271.

38 Trojer P, Li G, Sims RJ 3rd, et al. L3MBTL1, a histone-methylation-dependent chromatin lock. Cell 2007; 129:915-928.

39 Zhao Q, Rank G, Tan YT, et al. PRMT5-mediated methylation of histone H4R3 recruits DNMT3A, coupling histone and DNA methylation in gene silencing. Nat Struct Mol Biol 2009; 16:304-311.

40 Yang Y, Lu Y, Espejo A, et al. TDRD3 is an effector molecule for arginine-methylated histone marks. Mol Cell 2010; 40:1016-1023..

41 Kirmizis A, Santos-Rosa H, Penkett CJ, Singer MA, Green $\mathrm{RD}$, Kouzarides T. Distinct transcriptional outputs associated with mono- and dimethylated histone H3 arginine 2. Nat Struct Mol Biol 2009; 16:449-451.

42 Jin J, Cai Y, Li B, et al. In and out: histone variant exchange in chromatin. Trends Biochem Sci 2005; 30:680-687.

43 Macdonald N, Welburn JP, Noble ME, et al. Molecular basis for the recognition of phosphorylated and phosphoacetylated histone $\mathrm{H} 3$ by 14-3-3. Mol Cell 2005; 20:199-211.

44 Walter W, Clynes D, Tang Y, Marmorstein R, Mellor J, Berger SL. 14-3-3 interaction with histone H3 involves a dual modification pattern of phosphoacetylation. Mol Cell Biol 2008; 28:2840-2849.

45 Winget JM, Mayor T. The diversity of ubiquitin recognition: hot spots and varied specificity. Mol Cell 2010; 38:627-635.

46 Geng F, Tansey WP. Polyubiquitylation of histone H2B. Mol Biol Cell 2008; 19:3616-3624.

47 Lee JS, Shukla A, Schneider J, et al. Histone crosstalk between $\mathrm{H} 2 \mathrm{~B}$ monoubiquitination and $\mathrm{H} 3$ methylation mediated by COMPASS. Cell 2007; 131:1084-1096.

48 Zheng S, Wyrick JJ, Reese JC. Novel trans-tail regulation of $\mathrm{H} 2 \mathrm{~B}$ ubiquitylation and $\mathrm{H} 3 \mathrm{~K} 4$ methylation by the $\mathrm{N}$ terminus of histone H2A. Mol Cell Biol 2010; 30:3635-3645.

$49 \mathrm{Lu}$ X, Simon MD, Chodaparambil JV, Hansen JC, Shokat KM, Luger K. The effect of H3K79 dimethylation and H4K20 trimethylation on nucleosome and chromatin structure. Nat Struct Mol Biol 2008; 15:1122-1124.

50 Carrozza MJ, Li B, Florens L, et al. Histone H3 methylation by Set 2 directs deacetylation of coding regions by $\operatorname{Rpd} 3 \mathrm{~S}$ to suppress spurious intragenic transcription. Cell 2005; 123:581592.

51 Li B, Gogol M, Carey M, Lee D, Seidel C, Workman JL. Combined action of PHD and chromo domains directs the Rpd3S HDAC to transcribed chromatin. Science 2007; 316:10501054.

52 Murzina NV, Pei XY, Zhang W, et al. Structural basis for the recognition of histone $\mathrm{H} 4$ by the histone-chaperone RbAp46. Structure 2008; 16:1077-1085.

53 Martino F, Kueng S, Robinson P, et al. Reconstitution of yeast silent chromatin: multiple contact sites and O-AADPR binding load SIR complexes onto nucleosomes in vitro. Mol Cell 2009; 33:323-334.
54 Francis NJ, Kingston RE, Woodcock CL. Chromatin compaction by a polycomb group protein complex. Science 2004; 306:1574-1577.

55 Kashiwagi K, Nimura K, Ura K, Kaneda Y. DNA methyltransferase $3 \mathrm{~b}$ preferentially associates with condensed chromatin. Nucleic Acids Res 2011; 39:874-888.

56 Carrozza MJ, Florens L, Swanson SK, et al. Stable incorporation of sequence specific repressors Ash1 and Ume6 into the Rpd3L complex. Biochim Biophys Acta 2005; 1731:77-87; discussion 75-76.

57 Blackledge NP, Zhou JC, Tolstorukov MY, Farcas AM, Park PJ, Klose RJ. CpG islands recruit a histone H3 lysine 36 demethylase. Mol Cell 2010; 38:179-190.

58 Yap KL, Li S, Munoz-Cabello AM, et al. Molecular interplay of the noncoding RNA ANRIL and methylated histone H3 lysine 27 by polycomb $\mathrm{CBX} 7$ in transcriptional silencing of INK4a. Mol Cell 2010; 38:662-674.

59 Kanhere A, Viiri K, Araujo CC, et al. Short RNAs are transcribed from repressed polycomb target genes and interact with polycomb repressive complex-2. Mol Cell 2010; 38:675688.

60 Tsai MC, Manor O, Wan Y, et al. Long noncoding RNA as modular scaffold of histone modification complexes. Science 2010; 329:689-693.

61 Zhao J, Sun BK, Erwin JA, Song JJ, Lee JT. Polycomb proteins targeted by a short repeat RNA to the mouse X chromosome. Science 2008; 322:750-756.

62 Prasanth SG, Shen Z, Prasanth KV, Stillman B. Human origin recognition complex is essential for HP1 binding to chromatin and heterochromatin organization. Proc Natl Acad Sci USA 2010; 107:15093-15098.

63 Eskeland R, Eberharter A, Imhof A. HP1 binding to chromatin methylated at H3K9 is enhanced by auxiliary factors. Mol Cell Biol 2007; 27:453-465.

64 Fischle W, Tseng BS, Dormann HL, et al. Regulation of HP1chromatin binding by histone $\mathrm{H} 3$ methylation and phosphorylation. Nature 2005; 438:1116-1122.

65 Metzger E, Imhof A, Patel D, et al. Phosphorylation of histone H3T6 by PKCbeta(I) controls demethylation at histone H3K4. Nature 2010; 464:792-796.

66 Xhemalce B, Kouzarides T. A chromodomain switch mediated by histone H3 Lys 4 acetylation regulates heterochromatin assembly. Genes Dev 2010; 24:647-652.

67 Dawson MA, Bannister AJ, Gottgens B, et al. JAK2 phosphorylates histone H3Y41 and excludes HP1alpha from chromatin. Nature 2009; 461:819-822.

68 Botuyan MV, Lee J, Ward IM, et al. Structural basis for the methylation state-specific recognition of histone H4-K20 by 53BP1 and Crb2 in DNA repair. Cell 2006; 127:1361-1373.

69 Buhler M, Gasser SM. Silent chromatin at the middle and ends: lessons from yeasts. EMBO J 2009; 28:2149-2161.

70 Francis NJ, Follmer NE, Simon MD, Aghia G, Butler JD. Polycomb proteins remain bound to chromatin and DNA during DNA replication in vitro. Cell 2009; 137:110-122.

71 Carey M, Li B, Workman JL. RSC Exploits Histone Acetylation to Abrogate the Nucleosomal Block to RNA Polymerase II Elongation. Mol Cell 2006; 24:481-487.

72 Ruthenburg AJ, Li H, Patel DJ, Allis CD. Multivalent engagement of chromatin modifications by linked binding modules. 
Nat Rev Mol Cell Biol 2007; 8:983-994.

73 Gelbart ME, Bachman N, Delrow J, Boeke JD, Tsukiyama T. Genome-wide identification of Isw2 chromatin-remodeling targets by localization of a catalytically inactive mutant. Gene Dev 2005; 19:942-954.

74 Wang Y, Reddy B, Thompson J, et al. Regulation of Set9mediated H4K20 methylation by a PWWP domain protein. Mol Cell 2009; 33:428-437.

75 Lan F, Nottke AC, Shi Y. Mechanisms involved in the regulation of histone lysine demethylases. Curr Opin Cell Biol 2008; 20:316-325.

76 Dhayalan A, Rajavelu A, Rathert P, et al. The Dnmt3a PWWP domain reads histone 3 lysine 36 trimethylation and guides DNA methylation. J Biol Chem 2010; 285:26114-26120.

77 Jungmichel S, Stucki M. MDC1: The art of keeping things in focus. Chromosoma 2010; 119:337-349.

78 Ji Y, Resch W, Corbett E, Yamane A, Casellas R, Schatz DG.
The in vivo pattern of binding of RAG1 and RAG2 to antigen receptor loci. Cell 2010; 141:419-431.

79 Luco RF, Pan Q, Tominaga K, Blencowe BJ, Pereira-Smith OM, Misteli T. Regulation of alternative splicing by histone modifications. Science 2010; 327:996-1000.

80 Bell O, Schwaiger M, Oakeley EJ, et al. Accessibility of the Drosophila genome discriminates PcG repression, H4K16 acetylation and replication timing. Nat Struct Mol Biol 2010; 17:894-900.

81 Vogelauer M, Rubbi L, Lucas I, Brewer BJ, Grunstein M. Histone acetylation regulates the time of replication origin firing. Mol Cell 2002; 10:1223-1233.

82 Shen Z, Sathyan KM, Geng Y, et al. A WD-repeat protein stabilizes ORC binding to chromatin. Mol Cell 2010; 40:99-111.

83 Filion GJ, van Bemmel JG, Braunschweig U, et al. Systematic protein location mapping reveals five principal chromatin types in Drosophila cells. Cell 2010; 143:212-224. 